This item was submitted to Loughborough's Research Repository by the author.

Items in Figshare are protected by copyright, with all rights reserved, unless otherwise indicated.

\title{
Analyzing drivers' preferences and choices for the content and format of variable message signs (VMS)
}

\section{PLEASE CITE THE PUBLISHED VERSION}

https://doi.org/10.1016/j.trc.2019.01.013

\section{PUBLISHER}

Elsevier

\section{VERSION}

AM (Accepted Manuscript)

\section{PUBLISHER STATEMENT}

This paper was accepted for publication in the journal Transportation Research Part C: Emerging Technologies and the definitive published version is available at https://doi.org/10.1016/j.trc.2019.01.013.

\section{LICENCE}

CC BY-NC-ND 4.0

\section{REPOSITORY RECORD}

Zhao, Wenjing, Mohammed Quddus, Helai Huang, Jaeyoung Lee, and Zhuanglin Ma. 2019. "Analyzing Drivers' Preferences and Choices for the Content and Format of Variable Message Signs (VMS)". figshare. https://hdl.handle.net/2134/36822. 


\title{
Analyzing Drivers' Preferences and Choices for the Content and Format of Variable Message Signs (VMS)
}

\author{
Wenjing ZHAO', Mohammed QUDDUS², Helai HUANG*, Jaeyoung LEE³, Zhuanglin MA \\ ${ }^{1}$ School of Traffic and Transportation Engineering, Central South University, Changsha 410000, China. \\ 2 School of Architecture, Building and Civil Engineering, Loughborough University, Loughborough LE113TU, United \\ Kingdom. \\ ${ }^{3}$ Center for Advanced Transportation Systems Simulation, University of Central Florida, Orlando, FL 32816, United \\ States \\ ${ }^{4}$ School of Automobile, Chang'an University, Xi'an 710064, China. \\ *Correspondence: huanghelai@csu.edu.cn; Tel: +86-73182656631
}

\begin{abstract}
Background: Recent advance in variable message signs (VMS) technology has made it viable to provide spatio-temporal information on traffic and network conditions to drivers. There is a debate whether VMS diverts drivers' attention away from the road and may cause unnecessary distraction in their driving tasks due to inconsistent VMS contents and formats. There are also other external factors such as weather conditions, visibility and time of day that may affect the integrity and reliability of the VMS. In China, only about $23 \%$ drivers were persuaded by VMS to follow route diversion. Objective: In order to capture the full benefits of VMS, the aim of this paper is therefore to identify the factors affecting VMS by examining what kinds of VMS contents, formats and their interactions are more preferable to drivers, specifically in China. Methods: A revealed preference (RP) questionnaire and stated preference (SP) survey consisting of 1,154 samples from private and taxi drivers was conducted and analyzed using discrete choice model. Results: The results revealed that the information showed by amber-on-black on text format, white-on-blue on graph format or the suggested route diversion information showed by single line are preferred by drivers in fog weather. In addition, highly educated drivers or drivers with no occupation are more prone to the qualitative delay time on a text-graph format in fog weather. In normal weather, drivers with working trip purpose are mostly preferred to receive the information on a congested traffic condition with a reason on a text-only format. However, the congested traffic condition along with the information on the apparent causes shown by red-on-black or green-on-black on a text-only format was least preferred by drivers. Regarding current and adjacent road traffic information, drivers prefer to receive the suggested route diversion on a graph-only format in fog weather and the qualitative delay time on a text-graph format in normal weather. Irrespective to weather conditions, male drivers incline to the qualitative delay time on a text-graph format. Conclusions: The findings of this study could assist traffic authorities to design the most acceptable VMS for displaying traffic information for the purpose of improving road traffic efficiency and provide the theory evidence for the design of in-vehicle personalized information service system.
\end{abstract}

Key words: variable message signs (VMS), subjective measure, VMS contents, VMS formats, discrete choice models

\section{Introduction}

The daily physical transport of people and goods provided by current inefficient transport infrastructures, especially within city areas, is an increasingly serious problem in China. The continuous increase of vehicleownership, city logistics, urbanization and the growth for intercity mobility along with the insufficient infrastructure capacity at rush hours have led to the daily appearance of extended traffic gridlock and unprecedented levels of air pollution and traffic collisions in Chinese megacities. In addition to these serious consequences, public transport inadequacy, long commuting, high costs of infrastructure maintenance and a blatant lack of consideration for pedestrians and bicycles in the physical design of built environments and facilities are critical for the economic and social life of the affected metropolitan areas. This inevitably calls for a drastic and ground-breaking transform of current transport and mobility.

In order to alleviate these problems, authorities have implemented both conventional and smart solutions. On the one hand, traditional solutions focus on the increase of roadway capacity by building new roads which is, however, very costly. Smart solutions, on the other hand, aim to employ a range of ITS technologies, strategies and other transport demand management measures in order to reduce passenger car use and provide 
better public transport services (Bianco, 2000), car-pooling and vehicle-sharing schemes (Efthymiou et al., 2013). With respect to technological solutions, various intelligent transport systems have been implemented in managing demand to match the capacity available. These include: intelligent traffic signals (Balaji et al., 2010), ramp metering (Papageorgiou et al., 2004) and advanced traveler information system (ATIS) (Antoniou et al., 2011) through variable message signs (VMS). VMS, which is an infrastructure-based ATIS, has been proven to be an effective measure for alleviating traffic congestion caused by roadworks, special events, incidents and accidents affecting drivers' route diversion decisions (Mammar et al., 1996; Yim and Ygnace, 1996; Adler and Blue, 1998; Peeta and Ramos, 2006). VMS panels with respect to their design, installation and operation are, however, costly and overuse and inappropriate use of their contents may result in compromising their integrity (Wardman et al., 1997). Therefore, the effect of VMS on drivers' behaviors greatly depends on VMS contents and displayed formats (Boyle and Mannering, 2004). It is, therefore, very important for the traffic authorities to comprehend the likely preferences of motorists to different messages before designing and displaying them.

Dudek and Ullma (2002) seek to address several issues relating to how the information could be displayed so as to provide understandable and effective messages. The methods to determine what kinds of VMS content and format should be displayed are divided into two approaches: (i) subjective and (ii) objective method. The former is mainly focused on identifying what kinds of VMS contents and formats satisfy drivers' requirements, while the latter mainly measures which one has the minimum distraction time when drivers receive the information. Based on the objective approach, considerable research efforts have been made to identify the optimum VMS content and format using, for example, response accuracy (Richards, et al.,2004; Wang and Cao,2005; Lai, 2008, 2010,2012; Shinar and Vogelzang, 2013; Roca et al., 2018), response duration (Wang and Cao,2005; Yang et al.,2005; Wang et al., 2007; Lai, 2008, 2010, 2012; Shinar and Vogelzang, 2013; Roca et al., 2018), response distant (Williams et al., 2015; Roca et al., 2018) and gaze number (Roca et al., 2018). However, there is a dearth of research on the subjective measure to determine whether the displayed content and format of VMS is preferable to motorists. More importantly, subjective measures are often regarded as a complementary means to objective measures. Therefore, this study aims to satisfy drivers' requirement of information based on the subjective measure with three main objectives in mind:

1. To identify more preferable VMS contents, formats and their interactions;

2. To explore the effect of weather conditions on the drivers' choice

3. To draw policy implication on the design and display of VMS information.

\section{Literature review}

\subsection{Subjective measure for VMS contents and formats}

A number of researchers have explored drivers' attitude and preference for VMS content. Drivers were sensitive to the increased delay times. (Wardman et al., 1997; Al-Deek et al., 2012). Delays attribute to accidents have the larger impacts on route choice than other stated causes, such as roadworks and congestion (Wardman et al., 1997; Chatterjee et al., 2002; Spyropoulou and Antoniou, 2014; Sharples et al., 2016). Jindahra and Choocharukul (2013) employed the mixed logit model to analyze drivers' preference for VMS contents, the results showed that drivers would like to receive the suggested route diversion information, qualitative delay information and road construction information when they are at congested conditions. In addition, in terms of importance, the information was ranked in the following order: road construction, qualitative minute delay and suggested route information.

In order to identify the subjective attitude and preference of drivers for VMS formats, Yang et al. (2005) concluded that most subjects preferred the green and amber color combination. Moreover, if only one color was used, red was found to be the least preferred option. Wang et al. (2007) analyzed a set of statistical data and found that most participants preferred graphic-aided dynamic message signs over text-only dynamic message signs. In addition, amber was found to be the most preferred color in a dynamic message sign, followed by red and green. Conducting the preference survey after the experiment, Lai (2010) found that most participants preferred a two-color scheme and a double line message relative to the other combinations. Cristea and Delhomme (2014) developed an ANOVA technique to analyze drivers' attitudes toward pictograms. Their results showed that drivers expressed a positive attitude towards the pictograms accompanying by the text and considered them useful for the comprehension of the messages. Based on theory of affordances, Ronchi et al. (2016) indicated that flashing light, amber pictogram, the bigger size of the panels were preferred by 
participants when designing for the VMS for road tunnel emergency evacuations.

\subsection{Effect of driver's socio-economic characteristics}

Several studies have been conducted to develop an association between drivers' characteristics and VMS contents and formats. Benson (1996) found that drivers with higher education level fail to support for VMS displayed by a graph-only format. Trip purpose of the driver was not sensitive to the suggested route information (Emmerink et al., 1996; Kattan et al., 2010). Wardman et al., (1997) found that younger and female drivers were less influenced by the quantified delays information on the VMS panel. Drivers who were young, female, holding low educational qualifications or lower incomes find it difficult to understand the signs in relative to drivers who were older, male, holding high educational qualifications or higher incomes (Al-Madani and Al-Janahi, 2002a, 2002b). Gan and Ye (2011) found that drivers with rich experience are more sensitive to travel time saving information. Younger drivers required less response time with higher accuracy than older drivers and male drivers, in general, responded faster with lower accuracy than female drivers (Wang et al., 2005, 2007). Hassan and Abdel-Aty (2011) indicated that older drivers with more driving experience and less offences were more likely to obey warning messages displayed on changeable message signs under reduced visibility conditions and compared to young drivers. In addition, they were also more satisfied with the usefulness of advice or warning messages displayed on variable speed limit or changeable message signs. Shinar and Vogelzang (2013) employed the ANOVA technique to test the relationships between reaction time and drivers' age and years of licensed driving. Their results showed that there was a minimal decrease in reaction time with increasing age and years of licensed driving. Cristea and Delhomme (2014) found that young drivers expressed a more positive attitude to pictogram messages as compared to middle-aged ones and younger drivers spent less time to read and understand the messages as compared to older ones. Williams et al., (2015) found that older participants had a significantly shorter mean legibility distance for the amber-onblack sign but longer legibility distant for the black-on-amber sign than the younger participants in daytime fog weather. Moreover, younger participants observing the low-brightness signs had a significantly greater mean legibility distance than older participants in nighttime clear weather and a significantly longer mean detection distant than older participants in nighttime fog weather.

\subsection{Effect of traffic environment}

Traffic environment is also a key factor influencing driver's preference for VMS content and format. For instance, Hassan and Abdel-Aty (2011) developed a structural equation modeling approach to analyze drivers' behavior under reduced visibility conditions. Their results showed that drivers' satisfaction with variable speed limit or changeable message signs was found to be the most significant factor that positively affected drivers' compliance with advice or warning messages displayed on variable speed limit or changeable message signs under different fog conditions. Williams et al. (2015) explored the impact of different color configurations, brightness levels and flashing bacons on VMS on a driver's ability to detect and read the sign in four different conditions: daytime clear weather, daytime fog weather, nighttime clear weather, and nighttime fog weather. Results indicated that the high-brightness signs have the longer detection distance than low-brightness signs in daytime fog weather and red-on-black had a significantly greater mean legibility distance than black-on-amber in nighttime clear weather.

\subsection{Research approaches in designing VMS}

Different research methods were used to explore the influencing factors of drivers' understanding of messages and investigate what kinds of VMS contents and formats are more preferred by drivers. This includes: (i) revealed preference (RP) questionnaire surveys (Chatterjee et al., 2002; Kilpeläinen and Summala. 2007; Wang et al., 2009; Hassan and Abdel-Aty, 2011), stated preference (SP) questionnaire survey (Benson, 1996; Emmerink et al., 1996;Wardman et al., 1997; Al-Madani and Al-Janahi, 2002a, 2002b; Hassan and Abdel-Aty, 2011; Gan and Ye, 2011; Jindahra and Choocharukul, 2013; Spyropoulou and Antoniou, 2014; Ronchi et al., 2016) and a combination of SP and RP survey (Al-Deek et al., 2012), (ii) driving simulators (Mahmassani and Chen, 1991; Wang and Cao, 2005; Lai, 2008, 2012; Shinar and Vogelzang, 2013; Williams et al., 2015; Sharples, et al., 2016; Roca et al., 2018 ), and (iii) the combination of questionnaire survey and driving simulators (Yang et al., 2005; Wang et al., 2007; Lai, 2010; Cristea and Delhomme, 2014; Zhong et al., 2016). 
In summary, it can be concluded that although research has been conducted on drivers' attitude and preference for either VMS content or VMS format, there is a dearth of research on the drivers' preference for the interaction of VMS content and format. The undesirable interaction between VMS content and VMS format may divert motorists' attention away from the road for a considerable amount of time that can cause unnecessary distraction in their driving tasks as existing evidence indicates that looking away from the road for a period of two seconds or more increases a driver's risk of accidents and near accidents (Klauer et al., 2006). In addition, traffic environments, especially visibility conditions, significantly affect drivers' preference for VMS content and format. Therefore, this study aims to examine the driver's preference for the interaction of VMS content and format as well as to explore the effect of weather condition on drivers' choices.

\section{Method}

\subsection{Survey design}

As the participants were directly exposed to the VMS at the data collection points in Xi' an city, China, most of the survey questions were related to their experiences of using VMS and therefore, the survey is primarily a Revealed Preference (RP) survey. However, the respondents were also asked to answer few questions based on some hypothetical scenarios (e.g. investigating drivers' preference for VMS in fog/normal weather) so as to analyze driver' preference for VMS content and format. Therefore, the survey can be termed as a mixture of RP and SP (stated preference) surveys. A pictorial representation of the choice context was depicted in Figure1. Before the survey, a preliminary introduction of the survey purpose was presented in order to ensure the validity of data and the fieldwork was carried out during weekdays in May, 2015. In this study, data were collected by means of face-to-face on-site survey and an internet survey (In order to increase the sample size, a web link of survey was sent to the drivers who could not complete or fill the survey during the face-to-face on site questionnaire administration because of time constraint. Those drivers who received the web link were also requested to complete the survey on the same day.) distributed to private and taxi drivers at four petrol stations which are located at the downstream section of the VMS installations (Figure2). Therefore, it can be guaranteed that all participants had driven through the VMS locations before their completed the survey. Face-to-face onsite questionnaire were distributed to a total of 520 drivers, within which 473 questionnaires were returned giving a response rate of $90.96 \%$. A total of 212 respondents were obtained from the internet survey. Based on the data analysis, the results showed that more than $87 \%$ drivers often or always paid attention to VMS information (see Figure3). Survey data with incomplete information and drivers who seldom paid attention to VMS were excluded resulting in a total of 577 respondents. Considering that every driver was asked their preference for the interaction of VMS content and format in both fog and normal weather, respectively, the overall dataset has 1,154 samples. 


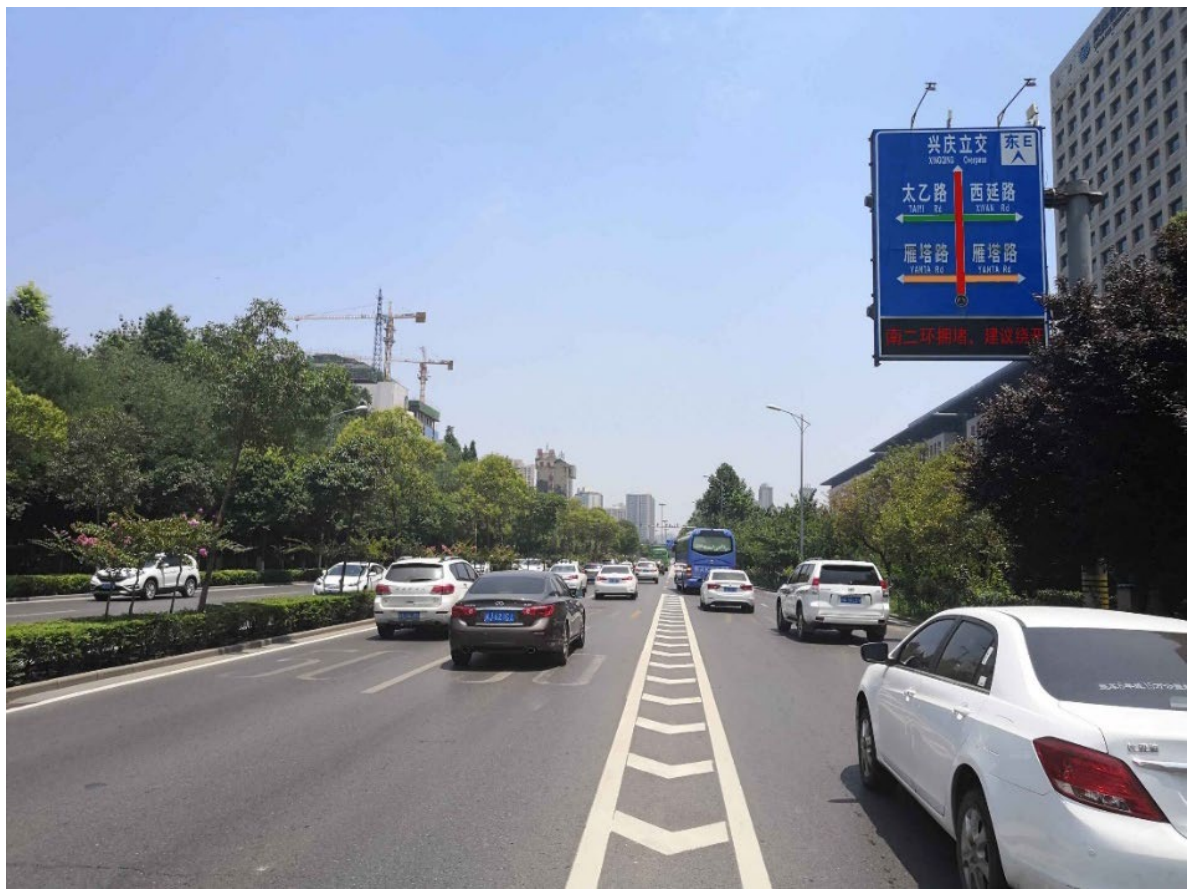

Figure 1 The example of the interactions of VMS contents and formats

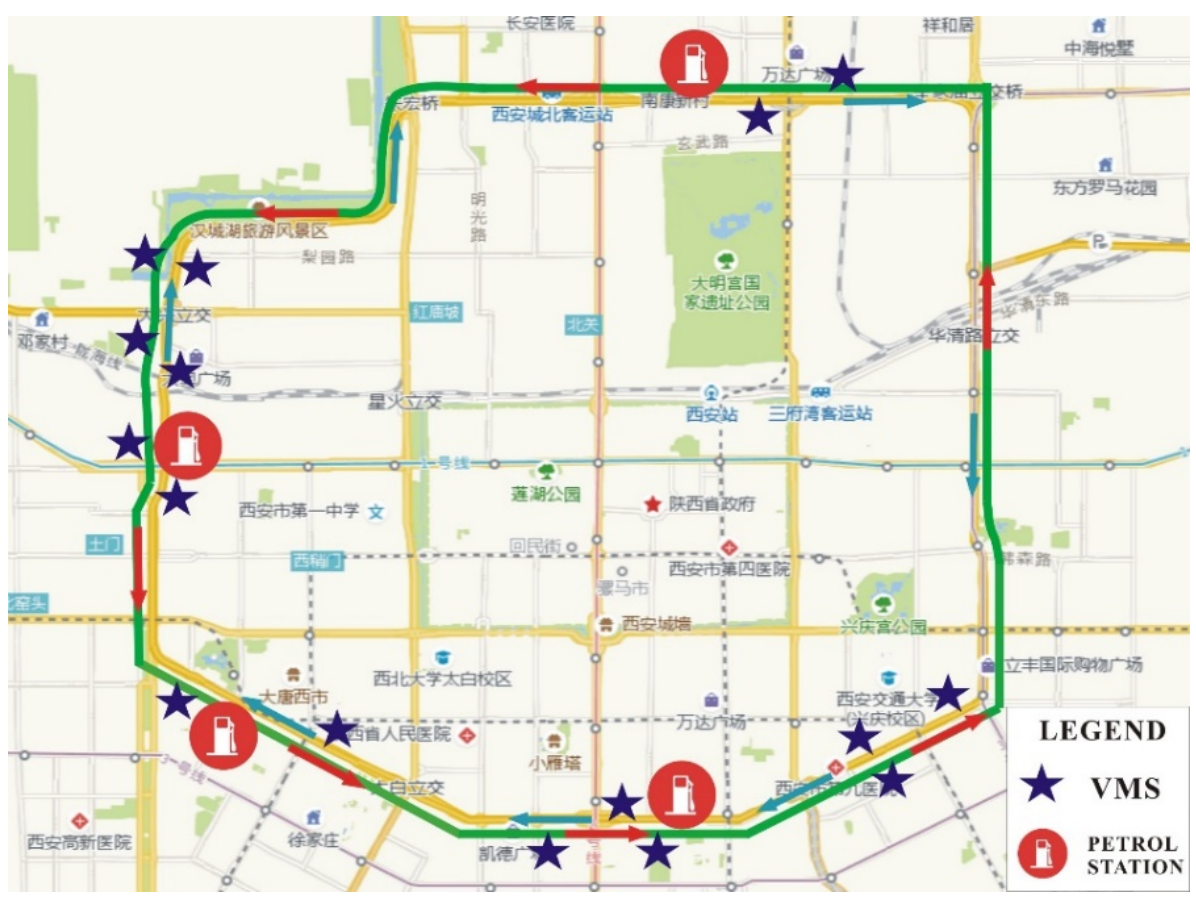

Figure 2 The location of survey 


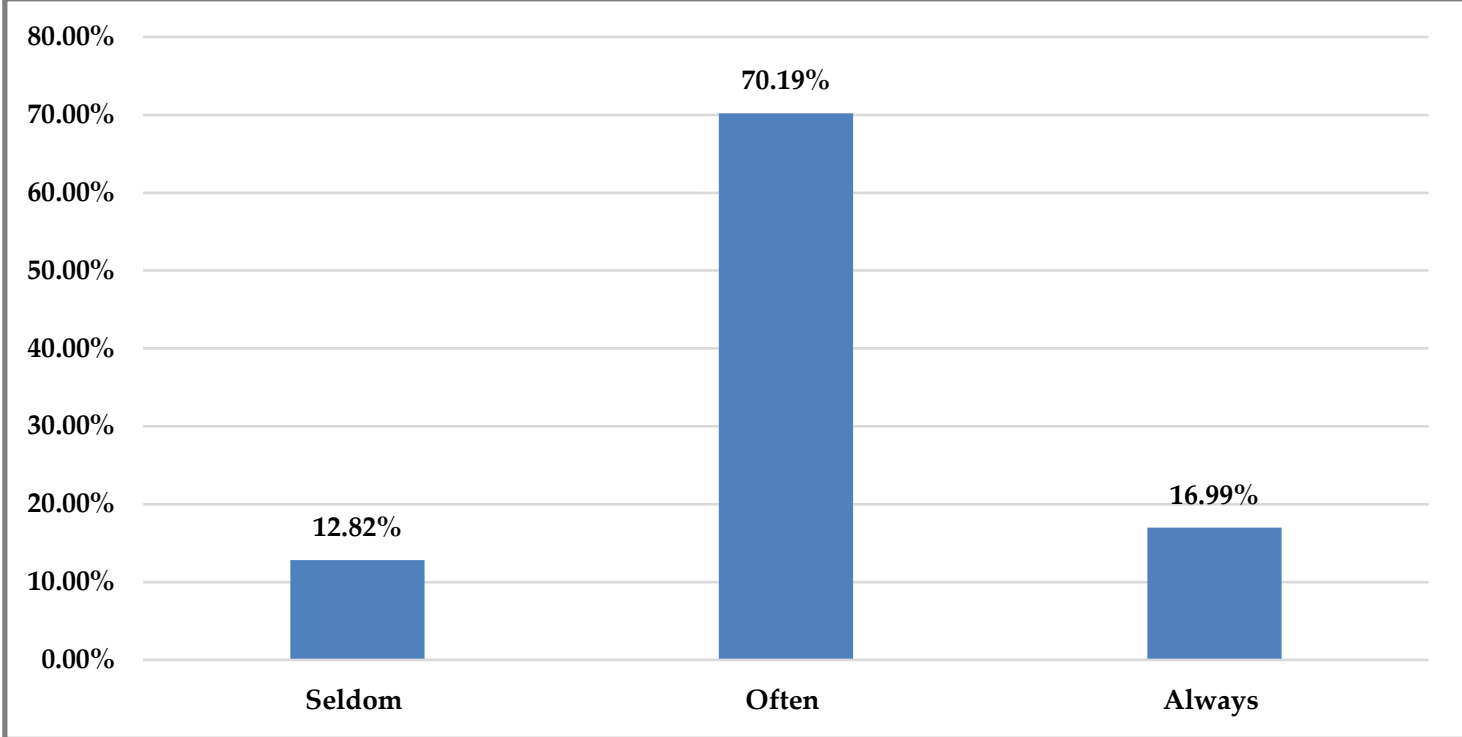

Figure 3 Drivers' attention to VMS

The questionnaire survey has a total of 12 questions divided into six parts: driver's preference for the interactions of VMS content and format, drivers' socio-economic characteristics (e.g., gender, driving experience, education level, occupation and monthly income), trip purpose, whether weather conditions affect their choice (When drivers' preference for VMS contents and formats in fog weather differs from their choice in the normal weather, it means that weather conditions affected drivers' choice for VMS format and content, i.e., 'Yes', or else 'No'.), road information attributes and VMS format attribute (e.g., the color of a text-only format, the color of a graph-only format, the color of a text-graph format and the number of lines or layers contained in message). The investigation for the color of three format preferred by drivers is based on the existing color design on the VMS panel. The summary statistics of variables and their abbreviations are presented in Table1.

Table 1 Variable description

\begin{tabular}{|c|c|c|c|}
\hline Variables & Code & Abbreviation & $\%$ \\
\hline Driver's preference for the & $1=$ Suggested route diversion information on a text-only format & Route-text & 13.86 \\
\hline interactions of VMS contents & $2=$ Suggested route diversion information on a graph-only format & Route-graph & 16.64 \\
\hline \multirow[t]{4}{*}{ and formats } & $3=$ Suggested route diversion information on a text-graph format & Route-text-graph & 28.60 \\
\hline & $4=$ Congested traffic condition with a reason on a text-only format & Congestion-text & 6.24 \\
\hline & $5=$ Qualitative delay time on a text-only format & Delay-text & 13.86 \\
\hline & 6= Qualitative delay time on a text-graph format(Reference case) & Delay-text-graph & 20.97 \\
\hline \multirow[t]{3}{*}{ Road information attribute } & $1=$ Current road information(Reference case) & CRI & 13.86 \\
\hline & $2=$ Current and alternative road information & CAR & 50.26 \\
\hline & $3=$ Current and adjacent road information & CJR & 35.88 \\
\hline \multirow[t]{3}{*}{ Color of text-only format } & $1=$ Amber-on-black(Reference case) & $\mathrm{ABT}$ & 41.33 \\
\hline & $2=$ Red-on-black & RBT & 23.21 \\
\hline & 3= Green-on-black & GBT & 35.46 \\
\hline \multirow[t]{3}{*}{ Color of graph-only format } & $1=$ White-on-green(Reference case) & WGG & 26.32 \\
\hline & $2=$ White-on-blue & WBG & 36.31 \\
\hline & $3=$ Amber-on-black & $\mathrm{ABG}$ & 37.37 \\
\hline \multirow[t]{3}{*}{ Color of text-graph format } & $\begin{array}{l}\text { 1=Amber-on-black on text format and white-on-blue on graph } \\
\text { format(Reference case) }\end{array}$ & ATWG & 64.51 \\
\hline & $2=$ Red-on-black on text format and white-on-blue on graph format & RTWG & 14.16 \\
\hline & $3=$ Green-on-black on text format and white-on-blue on graph format & GTWG & 21.33 \\
\hline
\end{tabular}




\begin{tabular}{|c|c|c|c|}
\hline \multirow[t]{2}{*}{ Gender } & $0=$ Female & - & 25.56 \\
\hline & 1=Male & - & 74.35 \\
\hline \multirow[t]{2}{*}{ Driving experience } & $0=$ More than 3 years & - & 49.91 \\
\hline & $1=$ Less than 3 years & - & 50.09 \\
\hline \multirow[t]{2}{*}{ Education level } & $0=$ Below Bachelor degree & - & 42.46 \\
\hline & 1= Bachelor degree and above & - & 57.54 \\
\hline \multirow[t]{2}{*}{ Occupation* } & $0=$ Fix occupation ${ }^{a}$ & - & 38.99 \\
\hline & $1=$ Free occupation $^{\mathrm{b}}$ & - & 61.01 \\
\hline \multirow[t]{2}{*}{ Monthly income * } & $0=$ More than $6000 \mathrm{RMB}$ & - & 22.36 \\
\hline & $1=$ Less than 6000 RMB & - & 77.64 \\
\hline \multirow[t]{2}{*}{ Trip purpose ${ }^{*}$} & $0=$ Non-official trip & - & 64.12 \\
\hline & 1=Official trip & - & 35.88 \\
\hline Number of message & 1=Single lines/layers(Reference case) & - & 15.08 \\
\hline \multirow[t]{2}{*}{ lines/layers } & 2=Double lines/layers & - & 65.68 \\
\hline & $3=$ Triple lines/layers & - & 19.24 \\
\hline Whether weather conditions & $0=\mathrm{No}$ & - & 38.13 \\
\hline affect their choice & $1=$ Yes & - & 61.87 \\
\hline
\end{tabular}

Note that the text-graph format has the two layers on graph format and various lines on text format.

a Fix occupation work as a full-time basis, such as commuter who uses the network regularly.

${ }^{b}$ Free occupation relative to unemployed (students and retired persons) or flexible workers who may occasionally use the network.

*Monthly income: we select the average monthly income(6000 RMB) in Xi' an city as a classification threshold

*Trip purpose, determined by arrival time, classified into less flexible trip (i.e., official trip,) and flexible trip (i.e., non-official trip)

\subsection{Statistical analysis}

The RP and SP experiment offered choices between six kinds of VMS panel information as shown in Table1. Since the dependent variable, is a nominal categorical variable, the most appropriate statistical method is a multinomial logit model (Horowitz, 1980). This is the most commonly employed discrete choice model in which we assume a sample of $N$ drivers with the choice of $I$ alternatives on a choice occasion $t$. The utility that a decision maker $n$ choosing alternative $i$ on a choice occasion $t$ has two parts: (i) representative or observed utility (i.e. $V_{\text {nit }}$ ) and (ii) a random component (i.e. $\varepsilon_{n i t}$ ) denoted as:

$$
U_{n i t}=V_{n i t}+\varepsilon_{n i t}
$$

The observed component $V_{n i t}$ dependent on a systematic part $X_{n i t} \beta_{i}$, where $X_{n i t}$ is a vector of relevant covariates (e.g., socio-economic characteristics, trip purpose, weather conditions at the time of travelling, road information attributes and VMS format attribute) confronting the individual $n$ on a choice occasion $t$ choosing alternative $i$, and $\beta_{i}$ is a vector of associated importance weights and the intrinsic preference of individual $n$ for decision $i$, which is captured by a fixed term, i.e., $\alpha_{n i}$. Hence, the random utility is given as follows:

$$
U_{n i t}=a_{n i}+X_{n i t} \beta_{i}+\varepsilon_{n i t}
$$

In which the random component captures the observed factors that not covered in the observed utility. The multinomial logit (MNL) model is therefore derived by assuming that each $\varepsilon_{n i}$ is independently and identically distributed (IID) extreme value known as Gumbel and type I extreme value distribution (Train, 2003). The probability that a participant maker $n$ chooses alternative $i$ on a choice occasion $t$ can be expressed as:

$$
P\left(y_{n t}=i\right)=\operatorname{prob}\left(a_{n i}+X_{n i t} \beta_{i}+\varepsilon_{n i t}>a_{n j}+X_{n j t} \beta_{j}+\varepsilon_{n j t}\right) \quad \forall j \neq i
$$

The MNL model probabilities are obtained by the following formula:

$$
P\left(y_{n t}=i\right)=\frac{\exp \left(a_{n i}+X_{n i t} \beta_{i}+\varepsilon_{n i t}\right)}{\sum_{j=1}^{J} \exp \left(a_{n j}+X_{n j t} \beta_{j}+\varepsilon_{n j t}\right)} \quad i=1,2,3, \ldots, I
$$


As every participant was asked to fulfill the questionnaire about their preference for VMS panel information (fog and normal weather), unobserved individual-level corrected effects and heterogeneity should be taken into account. However, the MNL model assumes that the random components of the utilities of different choice alternatives are IID and cannot capture the heterogeneity across participants. The mixed multinomial logit (MMNL) model offers significant advantages over the MNL model (e.g. McFadden and Train, 2000) by allowing for heterogeneity across participants. The random-parameter formulations of the MMNL model employs integration of the standard MNL choice probabilities over the assumed distribution of the random taste coefficients in that the probability of $n$ driver choosing $i$ on a choice occasion $t$ is given by:

$$
P\left(y_{n t}=i\right)=\int_{x} \frac{\exp \left(a_{n i}+X_{n i t} \beta_{i}+\varepsilon_{n i t}\right)}{\sum_{j=1}^{J} \exp \left(a_{n j}+X_{n j t} \beta_{j}+\varepsilon_{n j t}\right)} f(\beta \mid \theta) d \beta
$$

where $f(\beta \mid \theta)$ is a density function and $\theta$ is the vector of parameters to be estimated that represents, for instance, the mean and standard deviation of contributory factors.

In contrast to the random parameter model, an alternate means to accommodate unobserved heterogeneity among participants is through the use of latent class model. Both random parameter and latent class model assume that driver's behavior depends on additional factors beyond those that are directly observable. However, the latent logit model accommodates unobserved heterogeneity among study participants without any assumption as to the form of this underlying heterogeneity. Instead, the latent class logit model assumes individuals are implicitly sorted into a series $Q$ classes, with the classification unknown (i.e., unobserved) for a particular individual. It is assumed that parameters have identical effects within these class, but different effects between classes. The prior probability for class $q$ and individual $n$ follows the form of a logit model (Scarpa and Thiene, 2005):

$$
P(\text { class }=q)=\frac{\exp \left(Z_{n} \theta_{q}\right)}{\sum_{q=1}^{Q} \exp \left(Z_{n} \theta_{q}\right)} \quad q=1,2,3, \ldots, Q, Q=0
$$

where $Z_{n}$ denotes a set of individual characteristics that are associated with a class membership. $\theta_{q}$ is corresponding parameter for $q$ class. To ensure that the model is identifiable, the $Q^{\text {th }}$ parameter vector is arbitrarily normalized to zero (Greene and Hensher, 2003; Shen, 2009).

Within the class, choice probabilities are assumed to be generated by the multinomial logit model:

$$
P\left(y_{n t}=i \mid \text { class }=q\right)=\frac{\exp \left(a_{n i}+X_{n i t} \beta_{q}\right)}{\sum_{j=1}^{J} \exp \left(a_{n j}+X_{n j t} \beta_{q}\right)}
$$

where $\beta_{q}$ is class specific parameter vector.

The likelihood for individual $n$ is the expectation over all classed of the class-specific contributions:

$$
P\left(y_{n t}=i\right)=\sum_{q=1}^{Q} \frac{\exp \left(Z_{n} \theta_{q}\right)}{\sum_{q=1}^{Q} \exp \left(Z_{n} \theta_{q}\right)} \bullet \frac{\exp \left(a_{n i}+X_{n i t} \beta_{q}\right)}{\sum_{j=1}^{J} \exp \left(a_{n j}+X_{n j t} \beta_{q}\right)}
$$

\section{Results and Discussion}

A total of 12 explanatory variables, as discussed in the data analysis section, were examined. In selecting the final set of variables, many found to be statistically insignificant at the $95 \%$ confidence interval, then the insignificant variables were removed from the final model (a variable was remove if the $p$-value was more than 0.05). Additionally, to aid in interpreting the quantitative impacts of significant factors, the marginal effects for the model was calculated. For a dummy variable, the marginal effect means the change (increase or decrease) in probability that drivers' preference for VMS content, format and the interaction move from the reference case to the test category.

\subsection{Preference for VMS}

Table 2 and Figure 4 present the final modeling results and the marginal effects of the model, respectively. As illustrated in Table 2, there are many distributions that are supposed to use for the random parameters in 
MMNL model, such as normal, lognormal distribution, skewed normal, truncated normal, uniform, triangular, censored (left), censored (right) etc. However, only when the distribution is supposed to the censored (right), the results has the significant random parameters (i.e., amber-on-black (ABG) and red-on-black on text format and white-on-blue on graph format (RTWG)). Additionally, the standard deviation of RTWG is not listed because it is zero. Compared with a MNL and MMNL model, the two-class latent class logit model has a significantly improved goodness-of-it because it has the lower AIC as well as the higher log-likelihood and likelihood ratio. In addition, the latent class MNL models more than two classes could not be estimated because the membership probabilities in some classes are relatively small, leading to convergence problems. Compared with the MNL model, which cannot capture the heterogeneity across participants and the MMNL model, which considers the heterogeneity across participants by assuming the distribution of the random taste, the latent class logit model which does not follow any underlying heterogeneity assumption can accommodates unobserved heterogeneity among participants by classifying 577 participants into two classes (70\% and 30\%). This means that not all the individuals have the distinguishable unobserved heterogeneity across participants, but some individuals also have the unobserved homogeneity and the model can sort the individuals who are homogeneous into one group. With respect to implementation of VMS contents and formats, the operators shall focus on two homogeneous groups, i.e., when we provide VMS information for drivers, it makes sense that the published information designed according to the preference for VMS content and format of two group instead of every individuals.

With respect to the color of the text-only format, 70\% of motorists (Class1) are much more likely to prefer RBT (in comparison to amber-on-black, ABT) for 'route-text', 'congestion-text' and 'delay-text' alternative. This finding is, however, opposite for Class 2 motorists. More specifically, Red-on-black color has a positive impact (coefficient=0.59, $p=0.01$ ) on drivers' preference for a text-only format in Class 1 but a negative impact (coefficient $=-1.58, p=0.01$ ) in Class 2 , which indicates a $70 \%$ of the drivers prefer the VMS information to be displayed by RBT and the rest 30\% of the divers prefer the VMS information with ABT on a text-only format. This confirms inherent taste heterogeneity among the motorists as expected. Additionally, as to the overall sample, drivers are most likely preferred the congested traffic condition with reason information (i.e. congestion-text) (2.77\%) and least likely to the qualitative delay time information (i.e. delay-text) (-5.49\%) on a text-only format shown by RBT. It is inconsistent with previous works conducted by Yang et al. (2005), Wang et al. (2007), Lai (2008, 2010), who found that drivers showed strong preference for amber over red colored message on a text-only format. One possible explanation is the compatible relationship of VMS content and color. In order to ensure that the displayed color can make the VMS content easier to accepted by drivers, different content should be displayed in the corresponding color. Such as, a suggested route diversion information and a congested traffic condition with a reason should displayed by red-on-black while a qualitative delay time should be displayed by amber-on-black. The previous studies aim at exploring the effect of color but ignoring the effect of VMS content on drivers' choice for a text-only format, so they simply assume that the RBT decreases the probability of a text-only format preferred by drivers by adding all of them (i.e., $5.49 \%+2.77 \%+0.77 \%=-1.95 \%$, see Figure $4 a$ ). 
Table 2 Estimation result for MNL and latent class logit model ( $p$-value in the parentheses)

\begin{tabular}{|c|c|c|c|c|c|}
\hline & & & & Latent clas & git model \\
\hline & valiabie & MIIVL & HIVINLE & Class 1 & Class 2 \\
\hline Color of text-only form & (Red-on-black, RBT) & - & - & $0.59(0.01)$ & $-1.58(0.00)$ \\
\hline Color of graph-only for & hat (Amber-on-black, ABG) (Mean) & - & $0.55(0.03)$ & - & - \\
\hline $\begin{array}{l}\text { Color of graph-only } \\
\text { deviation) }\end{array}$ & format (Amber-on-black, ABT) (Standard & - & $2.47(0.00)$ & - & - \\
\hline Color of text-graph forn & at (RTWG) & - & $0.32(0.05)$ & $-0.57(0.01)$ & $2.23(0.01)$ \\
\hline Whether weather condi & ons affect their choice (Yes) & - & - & $-0.31(0.01)$ & $0.80(0.03)$ \\
\hline Suggested route & Number of message lines (Double lines) & $-0.56(0.02)$ & - & $-0.70(0.02)$ & - \\
\hline diversion information & Gender (Male) & $-0.48(0.04)$ & $-0.49(0.03)$ & - & - \\
\hline on a text-only format & Education level (Bachelor degree and above) & $-0.80(0.01)$ & $-0.84(0.00)$ & - & - \\
\hline (route-text) & Driving experience (More than 3 years) & - & - & $-1.25(0.01)$ & - \\
\hline & Occupation (Free occupation) & $-0.61(0.01)$ & $-0.70(0.01)$ & $-0.73(0.02)$ & - \\
\hline & Constant & $0.78(0.01)$ & $0.67(0.01)$ & $1.21(0.01)$ & $-9.42(0.97)$ \\
\hline Suggested route & Number of message lines (Double layers) & $0.44(0.05)$ & - & $1.10(0.01)$ & - \\
\hline diversion information & Driving experience (More than 3 years) & $-0.57(0.01)$ & - & $-1.92(0.04)$ & - \\
\hline on a graph-only & Occupation (Free occupation) & $-0.46(0.03)$ & $-0.41(0.05)$ & $-0.71(0.03)$ & - \\
\hline format (route-graph) & Trip purpose (Official trip) & - & - & $-0.88(0.04)$ & $4.82(0.00)$ \\
\hline & Constant & $-0.19(0.52)$ & $0.18(0.51)$ & $0.51(0.36)$ & $-3.26(0.03)$ \\
\hline Suggested route & Number of message lines (Double lines) & - & - & $-0.64(0.02)$ & - \\
\hline diversion information & Gender (Male) & $0.58(0.01)$ & $0.54(0.01)$ & - & - \\
\hline on a text-graph format & Education level(Bachelor degree and above) & - & $-0.37(0.03)$ & - & - \\
\hline (route-text and graph) & Driving experience (More than 3 years) & $-0.66(0.00)$ & - & $-1.78(0.00)$ & - \\
\hline & Occupation (Free occupation) & - & - & $0.62(0.04)$ & - \\
\hline & Constant & $0.24(0.35)$ & $0.09(0.68)$ & $1.46(0.01)$ & $-14.28(1.00)$ \\
\hline $\begin{array}{l}\text { Congested traffic } \\
\text { condition with a }\end{array}$ & $\begin{array}{l}\text { Whether weather conditions affect their } \\
\text { choice (Yes) }\end{array}$ & $0.88(0.00)$ & $-0.44(0.03)$ & - & - \\
\hline reason on a text-only & Number of message lines (Double lines) & - & - & - & $-1.57(0.05)$ \\
\hline format (congestion- & Driving experience (More than 3 years) & $-0.81(0.00)$ & - & - & - \\
\hline text) & Occupation (Free occupation) & $-0.60(0.01)$ & $-0.63(0.03)$ & $-1.39(0.00)$ & - \\
\hline & Trip purpose(Official trip) & - & - & $0.87(0.04)$ & - \\
\hline & Constant & $0.05(0.86)$ & $0.29(0.29)$ & $-0.82(0.27)$ & $1.32(0.09)$ \\
\hline Qualitative delay time & Driving experience (More than 3 years) & $-1.38(0.00)$ & - & - & - \\
\hline on a text-only format & Trip purpose (Official trip) & - & - & - & $3.44(0.01)$ \\
\hline (delay-text) & Constant & $-0.90(0.02)$ & $-1.05(0.04)$ & $12.01(0.99)$ & $-0.10(0.91)$ \\
\hline Class probabilities & & - & - & $0.70(0.00)$ & $0.30(0.00)$ \\
\hline Number of parameters & & 6 & 6 & & \\
\hline Constant-only likelihoo & & -1965.9082 & -1965.9082 & -196 & 082 \\
\hline Final log-likelihood & & -1889.1788 & -1921.5735 & -185 & 561 \\
\hline AIC & & 3848.4 & 3901.9 & & \\
\hline Likelihood ratio test vs & UNL model & & - & $\chi^{2}=5$ & $>3.84$ \\
\hline
\end{tabular}




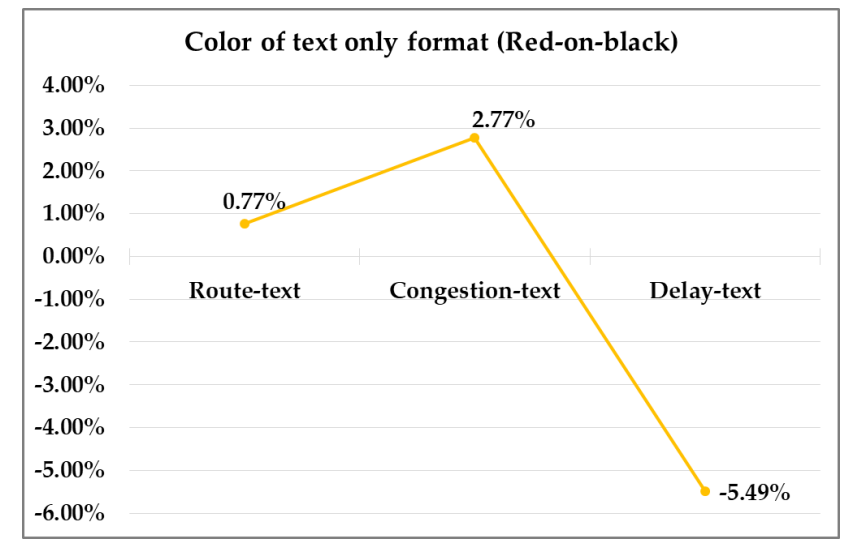

(a)

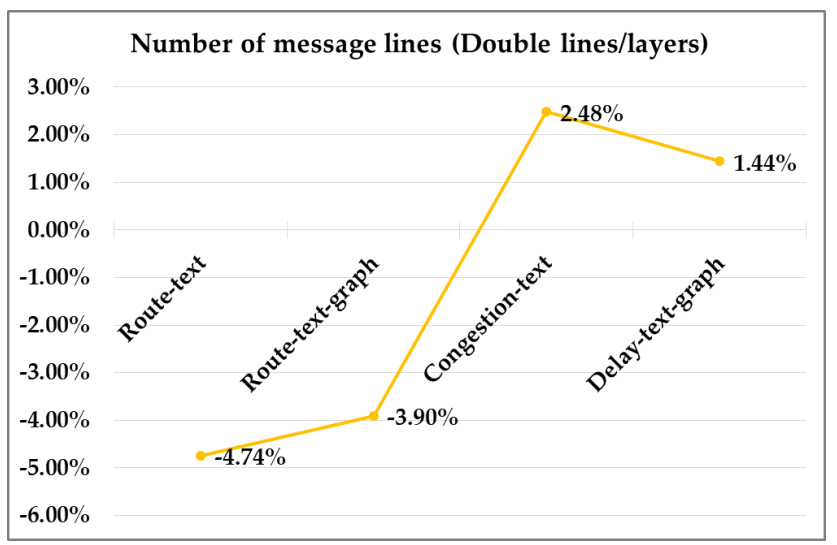

(c)

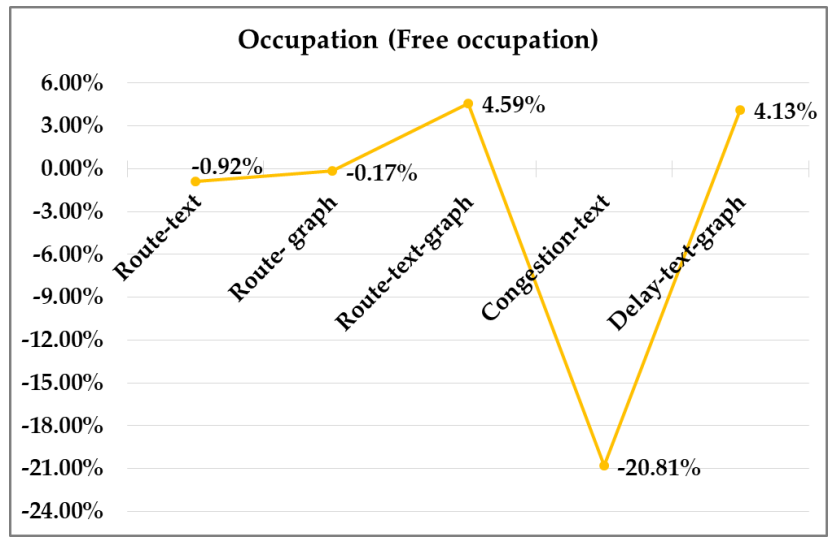

(e)

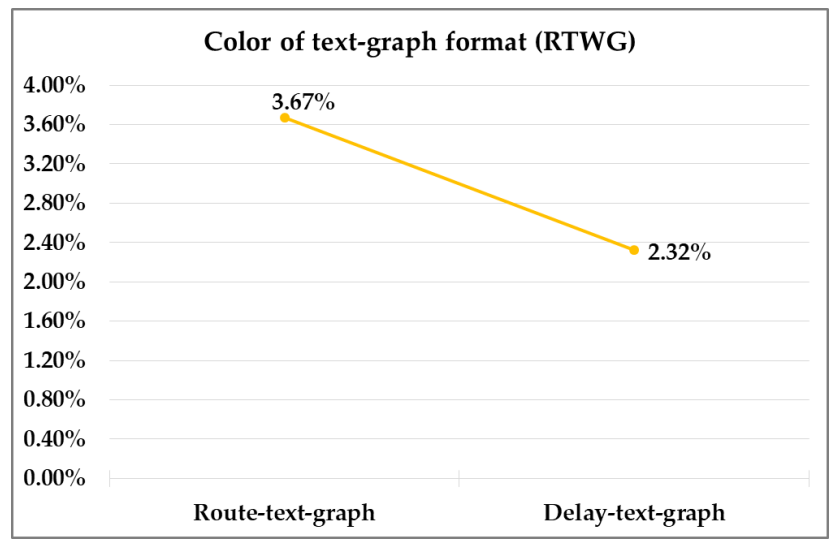

(b)

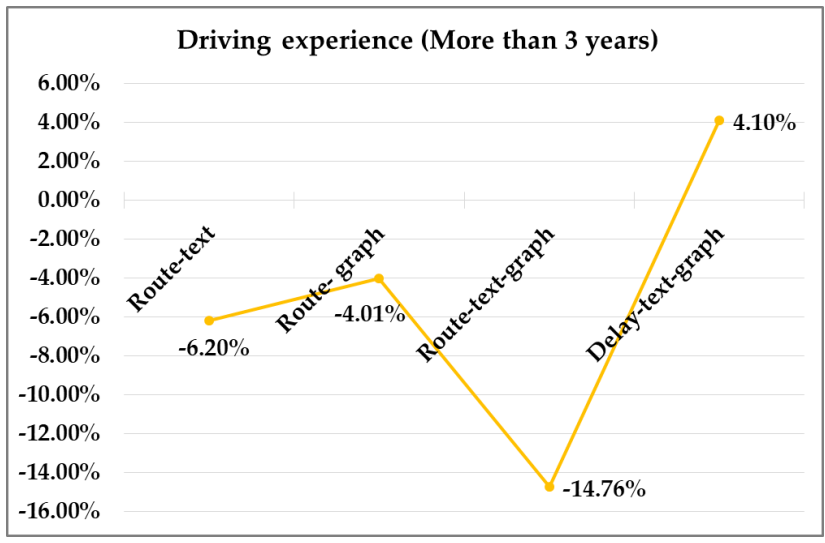

(d)

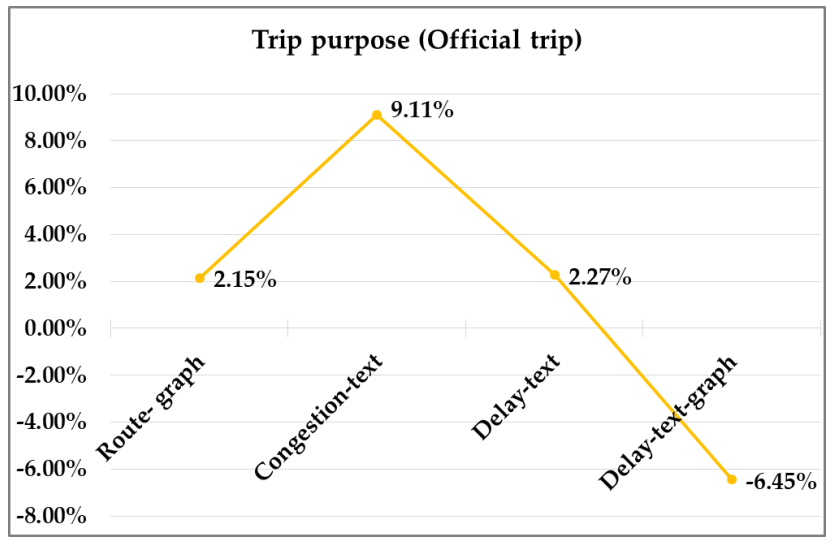

(f)

Figure 4 Marginal effect for predictor variables by model formulation

The negative coefficient of RTWG (coefficient $=-0.57, \mathrm{p}=0.01$ ) in Class 1 and the positive coefficient value of RTWG (coefficient $=2.23, p=0.01$ ) in Class 2 indicate that $70 \%$ of the drivers prefer the VMS information to be showed by amber-on-black on a text format and white-on-blue on a graph format (ATWG) whereas the rest $30 \%$ of the drivers prefer the VMS information showed by RTWG on a text-graph format (i.e. route-text-graph alternative and delay-text-graph). Nevertheless, RTWG, as compared to ATWG, was found to increase drivers' preference for a text-graph format $(3.67 \%$ and $2.32 \%)$ in the overall sample. This finding is also inconsistent with Wang et al., (2007), who found that drivers prefer amber-colored messages to red-colored messages shown on a graphic-aided format. One explanation of this finding is that the coefficient effect of small group (Class 2) on drivers' preference for the color of a text-graph format is much larger than the big group (Class 1), supporting most drivers' choice.

Regarding whether the weather conditions affect their choice, the negative value in Class1 (coefficient=- 
0.31, $p=0.01$ ) and the positive value in Class 2 (coefficient $=0.80, p=0.03$ ) indicate that this variable has a significantly different impact on these two-class drivers. Owing to all drivers' choice affected by weather conditions, the effect of weather condition on their choice cannot be explicitly illustrated. The detail explanation about how weather conditions affect drivers' choice is presented in section 4.2.

The variable - double lines shows a significantly negative value for the suggested route diversion information on a text-only format (route-text) (coefficient $=-0.70, p=0.02$ ) and the suggested route diversion information on a text-graph format (route-text-graph) (coefficient=-0.64, $p=0.02$ ) in Class 1 and the congested traffic condition with a reason on a text-only format (congestion-text) (coefficient=-1.57, $p=0.05$ ) in Class 2 . However, as a whole, double decrease the probability of route-text $(-4.74 \%)$ and route-text-graph $(-3.9 \%)$ and increase the probability of congestion-text $(2.48 \%)$ and delay-text-graph $(1.44 \%)$ preferred by drivers. The suggested route diversion information displayed by single line preferred by drivers because of this information only providing the suggested road for drivers, which is consistent with Wang and Cao (2005). However, differing from displaying the suggested route diversion information, the message in the congestion-text (i.e., the reason of congestion and the degree of congestion) and delay-text-graph (i.e., the qualitative delay time of obstructed and unobstructed road information) includes two different parts message, therefore two doubles lines message correspond to the different part message, which confirms a previous finding (Lai, 2010). In addition, double layers message has a positive impact on a suggested route diversion information on a graph-only format (route-graph) (coefficient=1.10, $p=0.01$ ), which indicates that drivers are more inclined to the suggested route diversion information on a graph-only showed by two layers.

More than 3 years of driving experience has a significantly positive correlation with route-text (coefficient=1.25, $p=0.01$ ), route-graph (coefficient=-1.92, $p=0.04$ ) and route-text-graph (coefficient=-1.78, $p=0.00$ ) in Class 1 , which indicate that compared with less than 3 years driving experience, drivers of Class 1 with more than 3 years driving experience are less preferable to the suggested route diversion information. Furthermore, as a whole, there is a clear downward trend for the probability of drivers' preference for the suggested route diversion information $(-6.20 \%,-4.01 \%$ and $-14.76 \%)$ as drivers' driving experience have more than 3 years. It is consistent with previous studies (Richard et al., 2004; Kattan et al., 2010; Zhong et al., 2012) which concluded that inexperienced drivers found VMS guidance information more useful and faced fewer problems while using VMS. In addition, Gan and Ye (2011) found that drivers' experience is positively related to familiarity with the network and some scholars (e.g. Bonsall and Joint, 1991; Mahmassani and Chen, 1991; Wardman et al., 1997; Ben-Elia et al., 2008; Zhong et al., 2012) revealed that drivers who were familiar with a network was likely to reduce independence on directional information while they increasing the ability to respond to traffic information.

Free occupation is found to be negatively correlated with route-text (coefficient=-0.73, $p=0.01$ ), route-graph (coefficient=-0.71, $p=0.03$ ) and congestion-text (coefficient=-1.39, $p=0.00$ ) but positively correlated with routetext-graph (coefficient $=0.62, p=0.04$ ) in Class 1 , which indicate that compared with qualitative delay time on a text-graph format (delay-text-graph), drivers of Class 1 with free occupation are prone to route-text-graph and less prone to route-text, route-graph and congestion-text. This variable increases the probability of route-textgraph $(4.59 \%)$ and delay-text-graph $(4.13 \%)$ as well as decreases the probability of route-text (-0.92\%), routegraph $(-0.17 \%)$ and congestion-text $(-20.81 \%)$ preferred by drivers in all samples. Evidence from the marginal effect means that drivers with free occupation are inclined to the suggested route diversion and qualitative delay time shown on a text-graph format. It is supported by the questionnaire data which demonstrated that the proportion of route-text-graph preferred by drivers with free occupation is largest (32.10\%), followed by delay-text-graph $(23.30 \%)$.

Compared with delay-text-graph, drivers of Class 1 with official trip purpose are more likely to congestiontext (coefficient=0.87, $p=0.04$ ) but less likely to route-graph (coefficient=-0.88, $p=0.04$ ), and drivers of Class 2 with official trip purpose are more inclined to route-graph (coefficient $=4.82, p=0.00$ ) and qualitative delay time on a text-only format (delay-text) (coefficient=3.44, $p=0.01$ ). For the overall sample, drivers travelling as part of the official trip are most likely inclined to the congestion-text $(9.11 \%)$, followed by delay-text $(2.27 \%)$, route-graph $(2.15 \%)$ and less likely inclined to the delay-text-graph (-6.45\%). it was consistent with Sharples et al. (2016) who found that the specific reasons of traffic congestion instead simple congestion were easier to make drivers trust it. However, this finding is inconsistent with the previous works (Jou et al., 2005; Jindahra and Choocharukul, 2013) which found that drivers preferred the guidance information to qualitative information. This may be explained by the previous works which they ignore the effect of various format on drivers' attitude to qualitative 
delay time, so they synthesize delay-text-graph and delay-text to a whole $(2.27 \%-6.45 \%=-4.18 \%)$. In addition, it was also inconsistent to some previous works (Emmerink et al., 1996; Kattan et al., 2010) found drivers with trip purpose were not sensitive to the suggested route information due to the fact that official trip purpose were usually more stressful and time constrained than no-official trip. This may be explained by the fact that because of the square network characteristics of Xi'an city, those drivers take less time to detour to the destination when they taking the suggested route diversion information.

\subsection{Fog weather against normal weather}

Since the effects of weather conditions on drivers' choice are still on its infancy, the separate latent class logit models are specified and estimated for fog weather and normal weather, respectively. The model estimation results highlighting the variables affecting drivers' choice for the interaction of VMS content and format under different weather conditions are illustrated in Table 3 and the marginal effects of fog weather and normal weather are shown in Figure5.

In normal weather, it is found that $77 \%$ drivers prefer the VMS information showed by green-on-black (GBT) or RBT and 23\% drivers prefer the VMS information showed by ABT on a text-only format. Moreover, GBT and RBT increase the probability of delay-text $(2.99 \%$ and $4.15 \%)$ and route-text $(0.06 \%$ and $0.08 \%)$ and decrease the probability of congestion-text $(-12.32 \%$ and $-5.45 \%)$ preferred by drivers (see Figure $5 a)$.

Regarding the color of a text-graph format, RTWG is significant in fog weather and insignificant in normal weather. In fog weather, the negative value of RTWG in Class 1 and the positive value of RTWG in Class 2 indicate that $67 \%$ drivers prefer to the information showed by ATWG and other drivers prefer to the information showed by RTWG on a text-graph format. Conversely the overall sample increased, RTWG clearly decrease the probability of a text-graph format $(-2.05 \%$ and $-8.67 \%)$ preferred by drivers in the fog weather.

In fog weather, drivers' preference for text format can be strongly influenced by the number of message lines. More specifically, the variable - double lines, as compared to single line, is found to decrease the probability of route-text $(-0.20 \%)$, route-text-graph $(-19.23 \%)$ and delay-text $(-0.04 \%)$ and increase the probability of delay-text-graph $(5.61 \%)$ preferred by drivers, which means that drivers prefer the suggested route diversion information showed by single line information, but as for the qualitative delay time information, drivers prefer a text-only format showed by single line and a text-graph showed by double line.

Current and adjacent road information(CJR) are found to be a positive association with route-graph in Class 1 but a negative association with route-text and delay-text in Class 2 and lead to increase the probability of route-graph $(25.06 \%)$ and decrease the probability of route-text $(-0.03 \%)$ and delay-text $(-0.11 \%)$ preferred by drivers in fog weather. However, in normal weather, compared with delay-text-graph, drivers are least likely to receive the congestion-text $(-19.15 \%)$, followed by delay-text $(-1.43 \%)$ of current and adjacent road.

Male is found to be a negative association with congestion-text and delay-text in fog weather as well as route-text, congestion-text and delay-text in normal weather, which indicates irrespective to weather conditions, compared with those choice, male drivers are most probable to prefer the delay-text-graph $(0.63 \%$ and $5.82 \%)$. Considering educational degree, drivers with Bachelor degree and above prefer delay-text-graph (3.76\%) to route-text (-0.18\%) and route-text-graph (-12.88\%) in fog weather. Another significant variable in fog weather is occupation and drivers with free occupation are much more inclined to the qualitative delay time information in fog weather, especially the information shown on a text-graph format $(8.97 \%)$. Additionally, drivers with official trip purpose has a positive impact on congestion-text, which indicate that drivers are most likely to congestion-text in normal weather, which is consistent with the overall sample. 
Table 3 Estimation results for fog weather and normal weather ( $p$-value in the parentheses)

\begin{tabular}{|c|c|c|c|c|c|}
\hline \multirow{2}{*}{\multicolumn{2}{|c|}{ Variable }} & \multicolumn{2}{|c|}{ Fog weather } & \multicolumn{2}{|c|}{ Normal weather } \\
\hline & & Class 1 & Class 2 & Class 1 & Class 2 \\
\hline \multicolumn{2}{|c|}{ Color of text-only format (Green-on-black, GBT) } & - & - & $3.78(0.00)$ & $-4.08(0.00)$ \\
\hline \multicolumn{2}{|c|}{ Color of text-only format (Red-on-black, RBT) } & - & - & $4.03(0.00)$ & $-2.78(0.00)$ \\
\hline \multicolumn{2}{|c|}{ Color of text-graph format (RTWG) } & $-2.28(0.00)$ & $6.95(0.02)$ & - & - \\
\hline Suggested route & Number of message lines (Double lines) & $-2.41(0.00)$ & $-5.47(0.03)$ & - & - \\
\hline diversion information & Road information attribute (CJR) & - & $-10.33(0.03)$ & - & - \\
\hline on a text-only format & Gender (Male) & - & - & $-1.51(0.00)$ & - \\
\hline \multirow[t]{3}{*}{ (Route-text) } & Education level (Bachelor degree and above) & $-2.17(0.00)$ & - & - & - \\
\hline & Occupation (Free occupation) & $-3.94(0.00)$ & $-6.28(0.04)$ & - & - \\
\hline & Constant & $-11.14(0.99$ & $-1.58(0.27)$ & $-2.40(0.00)$ & $-2.74(0.99)$ \\
\hline Suggested route & Road information attribute (CJR) & $1.64(0.02)$ & - & - & - \\
\hline diversion information & Occupation (Free occupation) & $-3.02(0.02)$ & - & - & - \\
\hline $\begin{array}{l}\text { on a graph-only format } \\
\text { (Route-graph) }\end{array}$ & Constant & $2.76(0.09)$ & $-17.05(0.99)$ & $0.56(0.41)$ & $-0.25(1.00)$ \\
\hline Suggested route & Number of message lines (Double lines) & $-1.46(0.05)$ & - & - & - \\
\hline diversion information & Education level (Bachelor degree and above) & $-1.06(0.02)$ & - & - & - \\
\hline \multicolumn{6}{|l|}{ (Route-text-graph) } \\
\hline Congested traffic & Road information attribute (CJR) & - & - & - & $-6.12(0.02)$ \\
\hline condition with a reason & Gender (Male) & $-1.43(0.04)$ & - & - & $-5.03(0.01)$ \\
\hline on a text-only format & Occupation (Free occupation) & $-5.45(0.00)$ & $6.60(0.04)$ & - & - \\
\hline \multirow[t]{2}{*}{ (Congestion-text) } & Trip purpose (Official trip) & - & - & - & $5.60(0.04)$ \\
\hline & Constant & $-3.23(0.99)$ & $-2.25(0.24)$ & $-3.23(0.00)$ & 9.73(0.05) \\
\hline Qualitative delay time & Number of message lines (Double lines) & $-2.36(0.04)$ & - & - & - \\
\hline on a text-only format & Road information attribute (CJR) & $-2.32(0.05)$ & - & - & $-6.94(0.00)$ \\
\hline \multirow[t]{3}{*}{ (Delay-text) } & Gender (Male) & $-5.89(0.02)$ & - & - & $-4.66(0.01)$ \\
\hline & Occupation (Free occupation) & $-3.20(0.02)$ & $6.25(0.04)$ & - & - \\
\hline & Constant & $3.66(0.04)$ & $-27.04(1.00)$ & $-20.85(1.00)$ & $12.35(0.02)$ \\
\hline \multicolumn{2}{|l|}{ Class probabilities } & $0.67(0.00)$ & $0.33(0.00)$ & $0.77(0.00)$ & $0.23(0.00)$ \\
\hline \multicolumn{2}{|l|}{ Constant-only likelihood } & \multicolumn{2}{|c|}{-982.9541} & \multicolumn{2}{|c|}{-981.7000} \\
\hline \multicolumn{2}{|l|}{ Final log-likelihood } & \multicolumn{2}{|c|}{-881.7030} & \multicolumn{2}{|c|}{-808.1384} \\
\hline \multicolumn{2}{|l|}{ AIC } & \multicolumn{2}{|c|}{1909.4} & \multicolumn{2}{|c|}{1730.3} \\
\hline
\end{tabular}




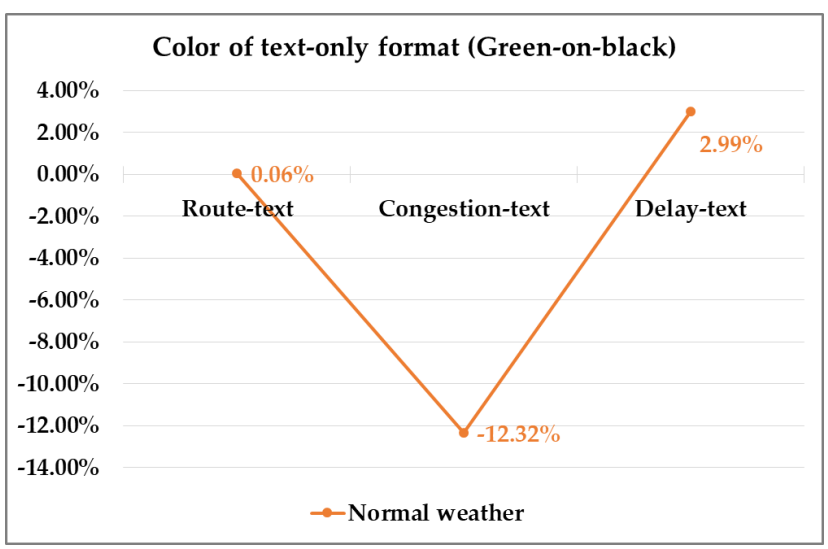

(a)

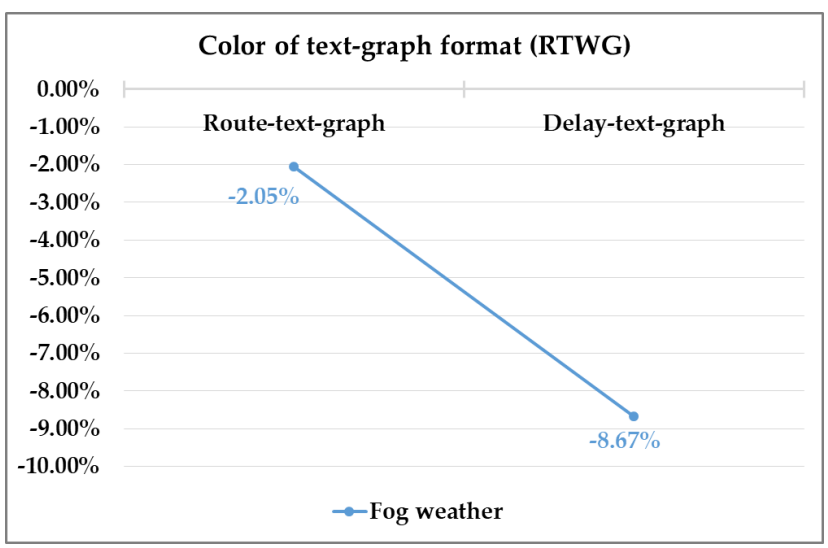

(c)

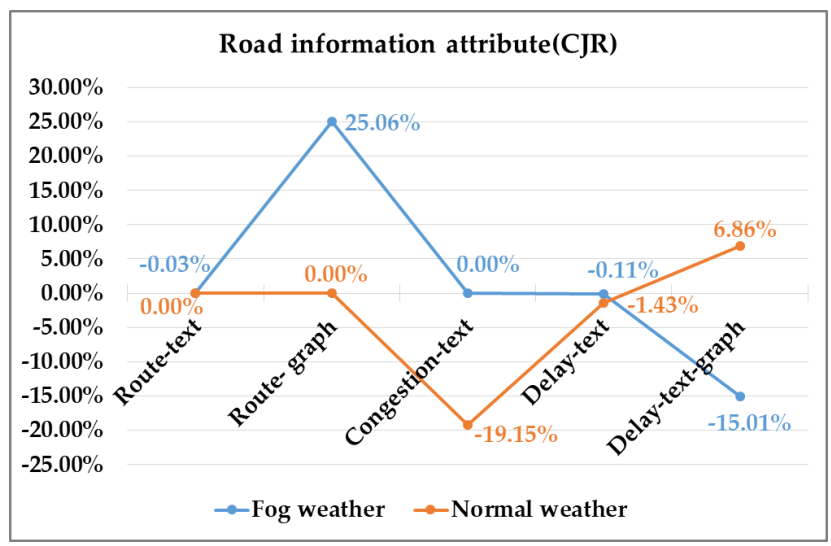

(e)

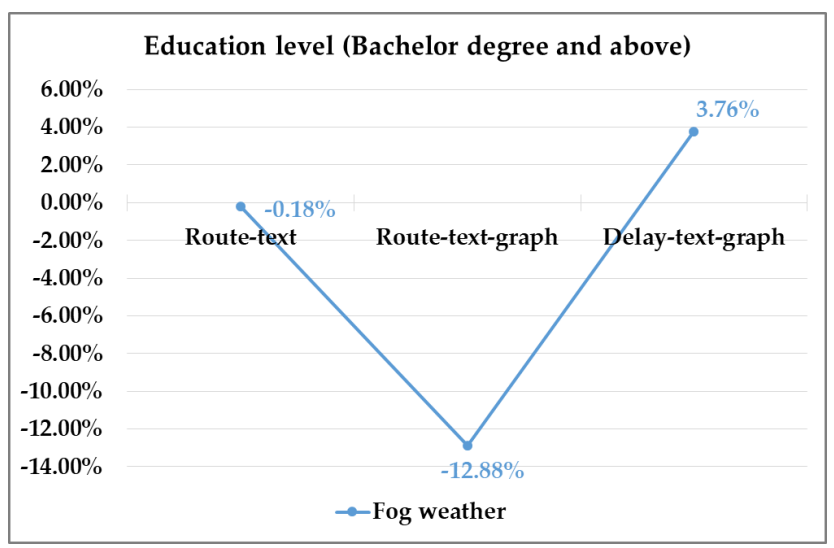

(g)

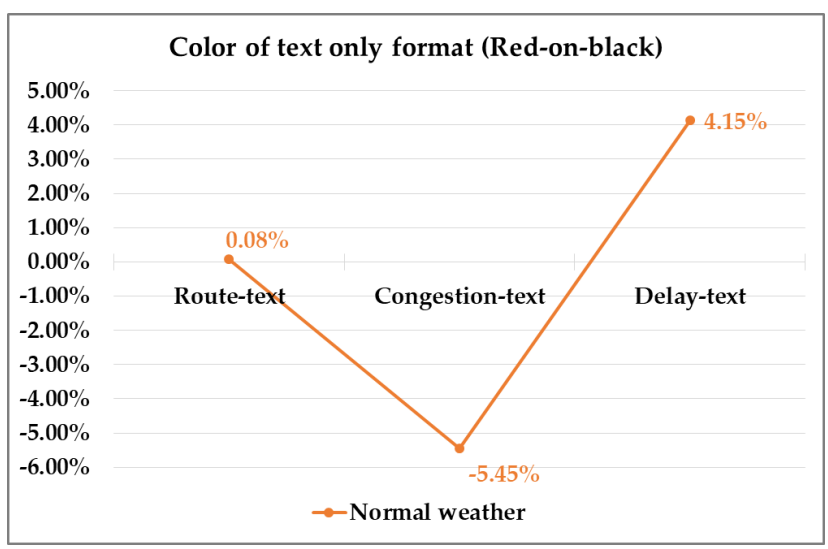

(b)

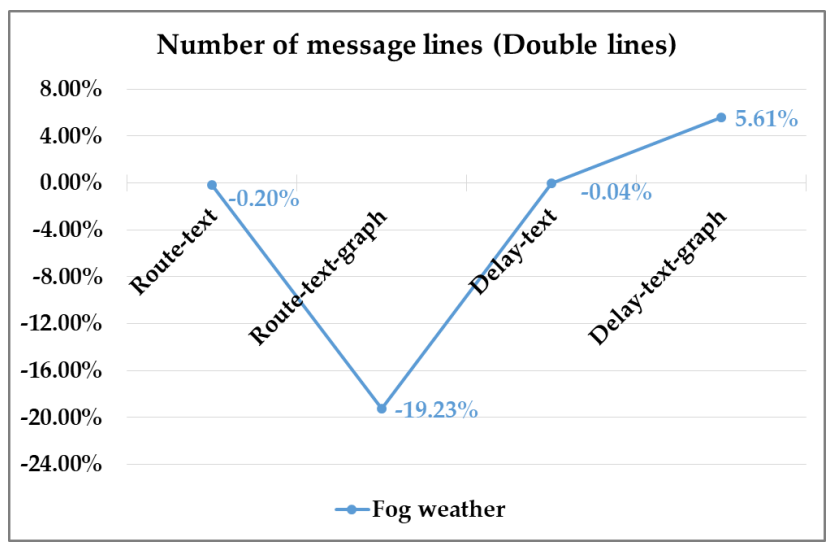

(d)

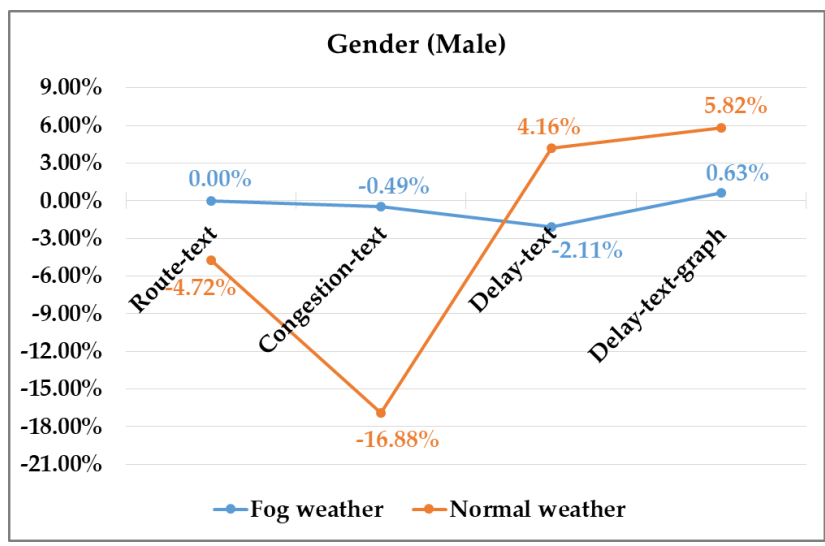

(f)

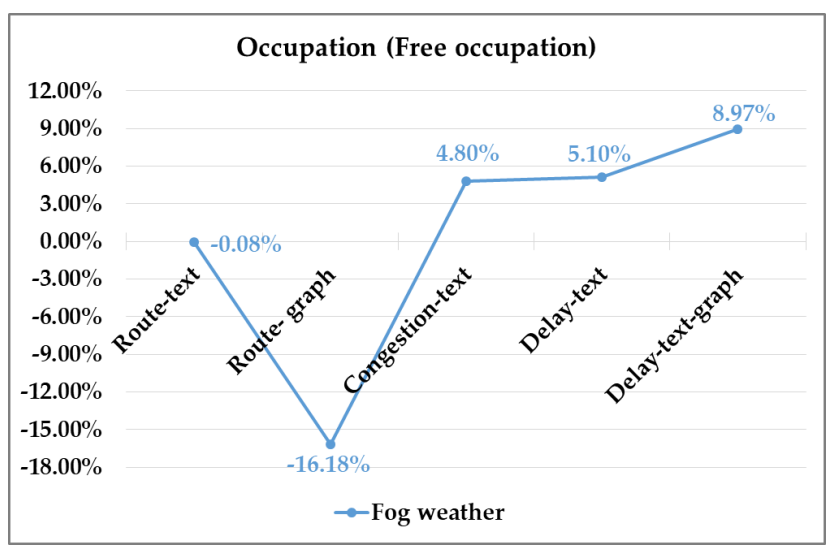

(h) 


\subsection{Policy Implications}

Findings from the modelling exercises have important implication for the design and display of roadside VMS information and for the design of personalized in-vehicle advanced driver assistance systems (P-ADAS).

Most notably, the color of text message, weather conditions and the number of message lines/layers have found to be very important factors in designing VMS panels and displaying mandatory and advisory information. Firstly, the appropriate compatibility of the VMS information and the color of the text message need be considered in order to make a VMS acceptable and reliable to motorists. For instance, the congested traffic conditions with the reason for the congestion should be displayed by ABT whereas the qualitative delay time information should be showed by RBT or GBT on a text-only format in normal weather. Secondly, regarding the suggested route diversion information, the text format showed by single line and a graph-only format by two layers are preferred by drivers. This means that any effective VMS format must be equipped with the suitable number of message lines/layers to instantly deliver the appropriate information to drivers in a short period of time. Finally, according to weather conditions, a roadside VMS panel is supposed to provide the desirable interactions of VMS content and format for drivers. For example, VMS panel should firstly provide the route-graph in fog weather as well as the delay-text-graph in normal weather for drivers about current and adjacent road when they are approaching the crossing.

As the finding that driver' characteristics can significantly influence drivers' preference for VMS content, the in-vehicle P-ADAS can therefore provide the personalized information for drivers by identifying drivers' individual characteristics. For instance, the in-vehicle system is supposed to provide the qualitative delay time information for the drivers when the system identifies the drivers who have free occupation, especially in fog weather, or the drivers who have more than 3 years driving experience and do not care about weather conditions. In addition, the system should first provide the congested traffic condition with a reason for the delay information for them when drivers inform the in-vehicle system about their trip purpose.

\section{Conclusions}

There has been a dearth of research on VMS contents and formats preferable to drivers. The objective of this paper was to facilitate the design and display of desirable VMS panels by examining what kinds of VMS content, format and their interactions are more preferable to drivers. Based on a RP and SP questionnaire survey completed by private and taxi drivers in $\mathrm{Xi}^{\prime}$ an, China, this study explored drivers' socio-economic characteristics, trip purpose, whether weather conditions affect their choice, road information attributes and VMS format attribute to build MNL models, MMNL models and latent class logit models. Two-class latent logit models outperform simple MNL models and MMNL models in all situations implying that there is unobserved taste heterogeneity between the sampled motorists.

The congested traffic condition with a reason information are preferred by drivers when the information is showed by RBT (red-on-black on a text format) or by drivers when they have a specific trip purpose (working trips). Drivers with no specific occupation prefer suggested route diversion and qualitative delay time information on a text-graph format. However, RTWG (Red-on-black on a Text format and White-on-blue on a Graph format) shown on a text-graph format are less preferred by most drivers. Regarding the suggested route diversion information, drivers are more likely inclined to a two-layer graph-only format and a single-line text format. Nevertheless, drivers with more than 3 years driving experience are less prone to the suggested route diversion information.

Based on the analysis on weather conditions, drivers have a positive attitude to the suggested route diversion information showed by single message line on a text format in fog weather and drivers with trip purpose prefer congestion-text most in normal weather, a consistent with the overall sample. However, conversely the overall sample increased, RBT decreases the probability of a congested traffic condition with a reason on a text-only format in fog weather and RTWG (red-on-black on a text format and white-on-blue on a graph format), as compared to ATWG (Amber-on-black on a Text format and White-on-blue on a Graph format), decreases the probability of a text-graph format in normal weather. Similar to the RBT, traffic condition with a reason on a text-only format showed by GBT (green-on-black color) is less preferred by drivers. The qualitative delay time information on a text-graph format was preferred by drivers when the information showed about the current and adjacent road in normal weather, or by highly educated drivers or driver without any 
occupation in fog weather or by male drives in any weather conditions. Additionally, drivers prefer the suggested route diversion on a text-only format of the current and adjacent road to the suggested route diversion and the qualitative delay time on a text-only format in fog weather.

In summary, the research has potential to improve the efficiency of variable message signs based on the available resources and design personalized in-vehicle advanced driver assistance systems. Furthermore, a number of findings would be conducive to design personalized information as a part of in-vehicle system in the future. The limitation of this study is that this paper solely conducted to the subjective measure to satisfy drivers' requirements, but neglected to employ the objective measure to identify whether drivers can obtain the information rapidly and accurately. Therefore, the combined use of data from subjective measure as well as objective measure might be recommended in future studies to address this concern.

\section{Acknowledgements}

This work was jointly supported by: 1) the Joint Research Scheme of National Natural Science Foundation of China/Research Grants Council of Hong Kong (Project No. 71561167001 \& N_HKU707/15), 2) National Key Research and Development Plan (No. SQ2018YFB120181), 3) the Nature Science Basic Research Program of Shaanxi Province (2017JM5084), 4) Humanities and Social Science Research Project of the Ministry of Education (No. 18YJCZH130).

\section{References}

Adler, J. L., Blue, V. J., 1998. Toward the design of intelligent traveler information systems. Transp. Res. Part C: Emerg. Technol. 6 (3), 157-172.

Al-Deek, H., Lochrane, T. W. P., Chandra, C. V. S. R., Khattak, A., 2012. Diversion during unexpected congestion on toll roads: the role of traffic information displayed on dynamic message signs. IET Intel. Transport Syst. 6(2), 97-106.

Al-Madani, H., Al-Janahi, A. R., 2002a. Role of drivers' personal characteristics in understanding traffic sign symbols. Accid. Anal. Prev. 34(2), 185.

Almadani, H., Al-Janahi, A. R., 2002b. Assessment of drivers' comprehension of traffic signs based on their traffic, personal and social characteristics. Transp. Res. part F: traffic Psychol. Behav. 5 (1), 63-76.

Antoniou, C., Koutsopoulos, H.N., Ben-Akiva, M., Chauhan, A.S., 2011. Evaluation of diversion strategies using dynamic traffic assignment. Transp. Plann. Technol. 34(3), 199-216.

Balaji, P. G., German, X., Srinivasan, D., 2010. Urban traffic signal control using reinforcement learning agents. IET Intel. Transport Syst. 4(3), 199-216.

Ben-Elia, E., Erev, I., Shiftan, Y., 2008. The combined effect of information and experience on drivers' routechoice behavior. Transportation 35(2), 165-177.

Benson, B. G., 1996. Motorist attitudes about content of variable-message signs. Transp. Res Rec. J. Transp. Res. Board 1550(1), 48-57.

Bianco, M., 2000. Effective transportation demand management: combining parking pricing, transit incentives, and transportation management in a commercial district of Portland, Oregon. Transp. Res Rec. J. Transp. Res. Board 1711(1), 46-54.

Bonsall, P. W., Joint, M., 1991. Driver compliance with route guidance advice: The evidence and its implications. Vehicle Navigation and Information Systems Conference 2, 47-59.

Boyle, L. N., Mannering, F., 2000. Impact of traveler advisory systems on driving speed: some new evidence. Transp. Res. Part C: Emerg. Technol. 12 (1), 57-72.

Chatterjee, k., Hounsell, N. B., Firmin, P. E., Bonsall, P. W., 2002. Driver response to variable message sign information in London. Transp. Res. Part C: Emerg. 10(2), 149-169.

Cristea, M., Delhomme P., 2014. Comprehension and acceptability of on-board traffic information: Beliefs and driving behavior. Accid. Anal. Prev. 65(2), 123-130. 
Dudek, C. L., Ullman, G. L., 2002. Flashing messages, flashing lines, and alternating one line on changeable message signs. Transport. Transp. Res Rec. J. Transp. Res. Board 1803(1), 94-101.

Efthymiou, D., Antoniou, C., Waddell, P., 2013. Factors affecting the adoption of vehicle sharing systems by young drivers. Transport Policy 29 (4), 64-73.

Emmerink, R. H. M., P. Nijkamp, P., Rietveld, J. N., Van Ommeren., 1996. Variable message signs and radio traffic information: an integrated empirical analysis of drivers' route choice behavior. Transp. Res. part A: Policy and Practice 30(2), 135-153.

Kilpeläinen, M., Summala, H., 2007. Effects of weather and weather forecasts on driver behaviour. Transp. Res. part F: traffic Psychol. Behav. 10 (4), 288-299.

Gan, H., Ye, X., 2011. Urban freeway users' diversion response to variable message sign displaying the travel time of both freeway and local street, IET Intell. Transp. Syst. 6(1), 78-86.

Greene, W. H., Hensher, D. A., 2003. A latent class model for discrete choice analysis: contrasts with mixed logit. Transp. Res. Part B: Methodol.37 (8), 681-698

Hassan, H. M, Abdel-Aty, M. A., 2011. Analysis of drivers' behavior under reduced visibility conditions using a structural equation modeling approach. Transp. Res. part F: traffic Psychol. Behav. 45(2), 614-625.

Horowitz, J., 1980. The accuracy of the multinomial logit model as an approximation to the multinomial probit model of travel demand. Transp. Res. Part B: Methodol.14 (4), 331-341.

Jindahra, P., Choocharukul, K., 2013. Short-run route diversion: An empirical investigation into variable message sign design and policy experiments. IEEE Transactions on Intelligent Transportation Systems 14(1), 388-397.

Jou, R. C., Lam, S. H., Liu, Y. H., Chen, K. H., 2005. Route switching behavior on freeways with the provision of different types of real-time traffic information. Transp. Res. part A: Policy and Practice 39(5), 445-461.

Kattan, L., Habib, K. M. N., Nadeem, S., Islam, T., 2010. Modeling travelers' responses to incident information provided by variable message signs in Calgary, Canada. Transp. Res Rec. J. Transp. Res. Board 2185(1), 71-80.

Klauer, S. G., Dingus, T. A., Neale, V. L., Sudweeks, J. D., Ramsey, D. J., 2006. The impact of driver inattention on near-crash/crash risk: An analysis using the 100-car naturalistic driving study data. U.S. department of transportation Washington DC.

Lai, C. J., 2008. An ergonomic study of Chinese font and color display on variable message signs. J. Chin. Ind. Eng. 25(4), 306-313.

Lai, C. J., 2010. Effects of color scheme and message lines of variable message signs on driver performance. Accid. Anal. Prev. 42(4), 1003-1008.

Lai, C. J., 2012. Drivers' comprehension of traffic information on graphical route information panels. Accid. Anal. Prev. 45(2), 565-571.

Mahmassani, H. S., Chen, P. S., 1991.Comparative assessment of origin-based and en-route real time information under alternative user behaviour rules. Transp. Res Rec. J. Transp. Res. Board 1306, 69-81.

Mammar, S., Messmer, A., Jensen, P., Papageorgiou, M., Haj-Salem, H., Jensen, L., 1996. Automatic control of variable message signs in Aalborg. Transp. Res. Part C: Emerg. Technol. 4 (3), 131-150.

Mcfadden, D, Train, K., 2000. Mixed MNL models for discrete response. Journal of Applied Econometrics 15(5), 447-470.

Papageorgiou, M., 2004. Overview of road traffic control strategies.In: Information and Communication Technologies: From Theory to Applications 91(12), 2043-2067.

Peeta, S., Ramos, J. L., 2006. Driver response to variable message signs-based traffic information. IEE Proceedings - Intel. Transport Syst. 153, 2-10.

Richards, A., McDonald, M., Fisher, G., Brackstone, M., 2004. Investigation of driver comprehension of traffic 
information on graphical congestion display panels using a driving simulator. European Journal of Transport and Infrastructure Research 4 (4), 417-435.

Roca, J., Tejero, P., Insa B., 2018. Accident ahead? Difficulties of drivers with and without reading impairment recognising words and pictograms in variable message signs. Appl. Ergon. 67, 83-90.

Ronchi, E., Nilsson, D., Modig, H., Walter, A.L., 2016. Variable Message Signs for road tunnel emergency evacuations. Appl. Ergon. 52, 253-264.

Scarpa, R., Thinen, M., 2005. Destination choice models for rock climbing in the northeastern Alps: a latent-class approach based on intensity of preferences. Land Econ. 81 (3), 426-444

Sharples, S., Shalloe, S., Burnett, G., Crundall, D., 2016. Journey decision making: the influence on drivers of dynamic information presented on variable message signs. Cogn. Tech. Work 18(2), 303-317.

Shen, J., 2009. Latent class model or mixed logit model? A comparison by transport mode choice data. Appl. Econ.41 (22), 2915-2924

Shinar, D., Vogelzang, M., 2013. Comprehension of traffic signs with symbolic versus text displays. Transp. Res. part F: traffic Psychol. Behav. 18(4), 72-82.

Spyropoulou, I., Antoniou, C., 2014. Determinants of driver response to variable message sign information in Athens. IET Intel. Transport Syst. 9(4), 453-466.

Train, K., 2003. Discrete Choice Methods with Simulation. Cambridge University Press, Cambridge, UK.

Wang, J. H., Cao Y., 2005. Assessing Message Display Formats of Portable Variable Message Signs. Transp. Res Rec. J. Transp. Res. Board 1973(1), 113-119.

Wang, J. H., Hesar, S. G., Collyer, C. E., 2007. Adding graphics to dynamic message sign messages. Transp. Res Rec. J. Transp. Res. Board 2018(2018), 63-71.

Wang, J.H., Keceli, M., Maier-Speredelozzi, V., 2009. Effect of Dynamic Message Sign Messages on Traffic Slowdowns. Transp. Res. Board 88.

Wardman, M., Bonsall, P. W., Shires, J., 1997. Driver response to variable message signs: a stated preference investigation. Transp. Res. Part C: Emerg. Technol 5(6), 389-405.

Williams, B., Gibbons, R., Medina, A., Connell, C., 2015. Visibility of a Color Variable Message Sign in the Fog. 94 Annual Meeting Transportation Research Board, National Academic, Washington, DC.

Yang, C. M, Waters, D., Cabrera, C. C., Wang, J. H., Collyer, C. E., 2005. Enhancing the Messages Displayed on Dynamic Message Signs. In: 3th International Driving Symposium on Human Factors in Driver Assessment, Training and Vehicle Design.

Yim, Y., Ygnace, J. L., Yim, Y., 1996. Link flow evaluation using loop detector data: traveler response to variablemessage signs. Transp. Res Rec. J. Transp. Res. Board 1550 (1), 58-64.

Zhong, S., Zhou, L., Ma, S., Jia, N., 2012. Effects of different factors on drivers' guidance compliance behaviors under road condition information shown on VMS. Transp. Res. Part A: Policy and Practice 46(9), 14901505. 